\title{
Mechanism of action of cariprazine
}

\author{
Stephen M. Stahl \\ ISSUE: \\ Cariprazine is a new therapeutic agent recently approved for the treatment of both \\ schizophrenia and manic or mixed episodes associated with bipolar disorder, and \\ is under investigation for the treatment of both bipolar depression and major \\ depressive disorder.
}

\section{Take-Home Points}

- Cariprazine is a dopamine multifunctional agent, but with pharmacologic properties that differentiate it from other agents in the atypical antipsychotic class.

- Cariprazine is a dopamine and serotonin $(5 \mathrm{HT})$ receptor partial agonist with intrinsic activity at the D2 dopamine receptor, similar to that of another new agent, brexpiprazole.

- High affinity actions of cariprazine at D3 dopamine receptors, as well as actions at 5HT1A, 5HT2A, and alpha $1 \mathrm{~B}$ receptors, differentiate it pharmacologically from other antipsychotics.

- Clinical differentiation from other antipsychotics is only now evolving with a head-to-head comparison with risperidone showing superiority for negative symptoms of schizophrenia, but no other comparative studies. Differentiation therefore is mostly based on preclinical models that suggest potential for improved tolerability in terms of weight gain, somnolence, and perhaps akathisia, as well as unique pro-cognitive and negative symptoms efficacy in schizophrenia.

A new dopamine D2 receptor partial agonist, cariprazine, has been approved both for the treatment of schizophrenia and manic or mixed episodes associated with bipolar I disorder. Since cariprazine (Figure 1$)^{1}$ has some pharmacologic properties related to those of other antipsychotics, including the new agent brexpiprazole, ${ }^{1,2}$ the question naturally arises: What differentiates cariprazine from other agents in its class?

\section{Cariprazine Has About the Same Intrinsic Activity as Brexpiprazole, but Less than Aripiprazole}

The dopamine agonist spectrum goes from "silent" antagonism on the far left of Figure 2, which is pure antagonism without any agonist activity, to "full" agonism on the far right of Figure 2, which is the maximum amount of stimulation of the D2 receptor. ${ }^{1}$ Almost all antipsychotics are silent antagonists and lie to the far left on the spectrum. Dopamine itself is a full agonist and lies to the far right on the spectrum.

Note that toward the left-hand part of the spectrum lie several interesting compounds that have been tested as antipsychotics. Those furthest to the right among this cluster (OPC 4392 and bifeprunox) seem to be too activating to be effective antipsychotics due to having too much of a dopamine "kick," more precisely, too much intrinsic activity. ${ }^{1}$ Aripiprazole has a bit less intrinsic activity (ie, it lies more toward the left-hand side of the spectrum of Figure 3), yet aripiprazole's clinical profile of activation, agitation and akathisia in some patients, suggests that it has too much intrinsic activity for them. Thus, the pharmacology of cariprazine "dialed down" the intrinsic activity another notch (Figure 3) to theoretically generate receptor binding properties at the D2 receptor that would make it less activating and possibly have a better overall tolerability profile as an antipsychotic than aripiprazole, and in this respect more comparable to brexpiprazole. $^{1,2}$ 


\section{BRAINSTORMS -Clinical Neuroscience Update}

\section{Cariprazine Has Unique Potent Binding for D3 Receptors and Other Unique Receptor Actions}

Essentially all antipsychotics are both D2 and D3 dopamine receptor antagonists or partial agonists (see for example Figure 3). ${ }^{1}$ However, the low affinities of current antipsychotics for the D3 receptor relative to the very high affinity of dopamine itself for the D3 receptor means that in the living brain, the D3 receptor is not blocked by any antipsychotic other than cariprazine because of the presence of dopamine. ${ }^{3-5}$ That is, because cariprazine is unique among antipsychotics in having a higher potency for the D3 receptor than dopamine itself

Figure 1. Pharmacologic properties of cariprazine shown qualitatively as an icon above and quantitatively as a binding strip below. The binding strip is composed of a series of boxes for potency of binding of the drug at each individual neurotransmitter receptor indicated. Boxes are placed in rank order of how potently cariprazine binds to the receptors, with the most potent and largest boxes to the far left and the weakest binding and smallest boxes to the far right. The vertical line indicates binding at the D2 dopamine receptor, generally targeted for $60-80 \%$ occupancy in the treatment of schizophrenia. Thus, boxes to the left of this generally indicate greater degrees of occupancy at these receptors at therapeutic doses; boxes to the right generally indicate lower degrees of occupancy at these receptors at therapeutic doses. Except for the D3 receptor, almost all receptors have binding affinities lower than that for the D2 receptor for cariprazine.

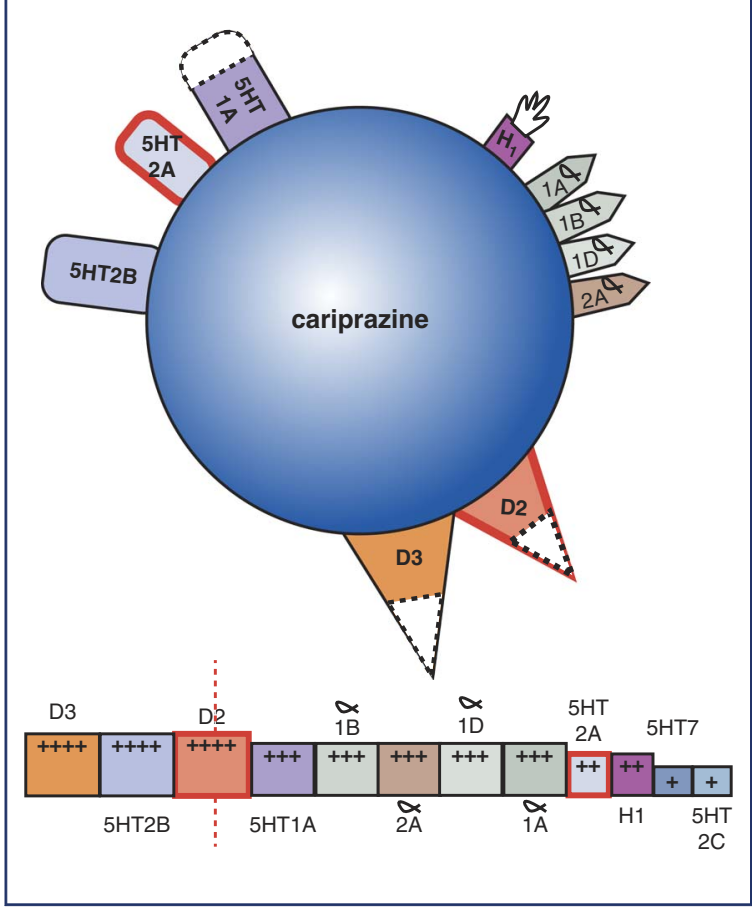

(Figure 3), ${ }^{3-5}$ the net effect of cariprazine administration is D3 receptor blockade. The consequences of D3 receptor blockade for patients with schizophrenia are unknown, but preclinical studies suggest that such an action could be pro-cognitive, antidepressant, active on negative symptoms (unpublished abstract from the 2015 ECNP Meeting) and even be helpful in stimulant abuse. ${ }^{6-8}$ Only further experience with cariprazine in practice will answer the question of what are the clinical correlates of uniquely blocking D3 receptors at the same time that D2 receptors are blocked.

Cariprazine has relatively high affinity for 5HT1A receptors (Figure 4), like many other antipsychotics, but lower relative affinity for 5HT2A receptors (Figure 4), unlike essentially any other atypical antipsychotic. ${ }^{1,5}$ The clinical consequences of this are at present unknown. However, cariprazine also has relatively high affinity for the alpha $1 \mathrm{~B}$ receptor, like brexpiprazole (Figure 5). ${ }^{1,5}$ High affinity at the alpha $1 \mathrm{~B}$ receptor is hypothetically linked to reduced extrapyramidal symptoms (EPS) and akathisia. ${ }^{1,9}$

\section{Cariprazine and Its Active Metabolite Have Uniquely Prolonged Half-Lives}

Cariprazine has a half-life of 2-4 days with an active metabolite that has a half-life of 1-3 weeks, the longest of any atypical antipsychotic. ${ }^{10-12}$ By comparison, aripiprazole and brexpiprazole also have long half-lives, but they and their active metabolites span 3-4 days, not weeks. ${ }^{10,11}$ The consequences of a very long half-life for cariprazine are 2-fold. First, when starting cariprazine, since it takes about 5 half-lives to get to steady state, it means that the effective dose is rising for many weeks after initiating a dose, even if the daily dose stays the same. This could lead the unsuspecting clinician to increase the dose before arriving at steady state and overshoot the ideal dose, requiring some down-titration later. Second, upon stopping cariprazine, it will be many weeks before the active drug is washed out. That could be a potential advantage in schizophrenia, a condition known to be characterized by poor compliance. The implications are that missing a dose here and there would not have as potentially devastating an effect on relapse as short half-life compounds, but this is yet to be proven in clinical trials.

\section{Efficacy and Safety}

Efficacy and safety of cariprazine for schizophrenia and for manic and mixed episodes of bipolar I disorder have 


\section{BRAINSTORMS-Clinical Neuroscience Update}

Figure 2. The dopamine agonist spectrum goes from "silent" antagonism on the far left, which is pure antagonism without any agonist activity, to "full" agonism on the far right, which is the maximum amount of stimulation of the D2 receptor. Almost all antipsychotics are silent antagonists and lie to the far left on the spectrum. Dopamine itself is a full agonist and lies to the far right on the spectrum. Novel antipsychotics lie between these 2 extremes, but closer to the antagonist end of the spectrum. OPC 4392 and bifeprunox seem to have too much of a dopamine "kick," more precisely, too much intrinsic activity, or too far to the right on the spectrum, and have failed as effective antipsychotics. Aripiprazole has a bit less intrinsic activity, yet its clinical profile of activation, agitation, and akathisia in some patients suggests that it has too much intrinsic activity for them. Both cariprazine and brexpiprazole "dialed down" the intrinsic activity another notch, to theoretically generate receptor binding properties at the D2 receptor that would make it less activating and possibly have a better overall tolerability profile compared to aripiprazole.

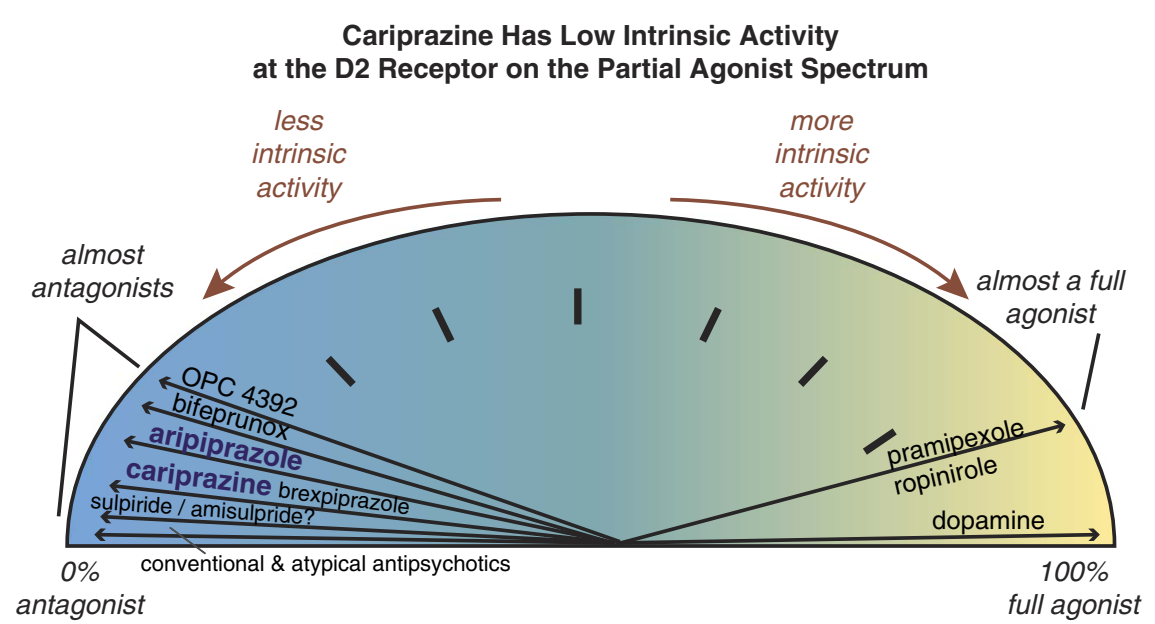

Figure 3. Comparing D3 dopamine receptor binding of cariprazine, brexpiprazole, and aripiprazole. The D2 receptor affinity for all compounds is highlighted by a vertical dotted line. The affinity of all 3 compounds for the D3 receptor is indicated, showing the very high affinity of cariprazine for the D3 receptor compared to the other antipsychotics. The affinity is so high for cariprazine that it is functionally higher than the affinity of the dopamine itself for the D3 receptor. This means that in the presence of dopamine in the living human brain, cariprazine is the only antipsychotic that blocks D3 receptors.

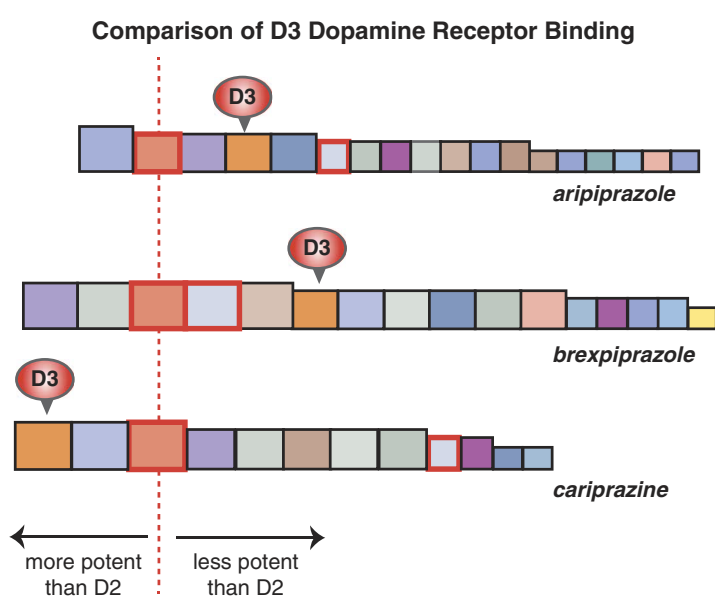




\section{BRAINSTORMS—Clinical Neuroscience Update}

Figure 4. Comparing serotonergic 5HT1A and 5HT2A

receptor binding of cariprazine, brexpiprazole, and

aripiprazole. The $\mathrm{D} 2$ receptor affinity for all compounds is

highlighted by a vertical dotted line. The 5HT1A

and 5HT2A receptor binding affinities for these

compounds are labeled in this figure. Cariprazine has

relatively high $5 \mathrm{HT} 1 \mathrm{~A}$ receptor binding affinity

and relatively low $5 \mathrm{HT} 2 \mathrm{~A}$ receptor binding

affinity.

Comparison of 5HT1A and 5HT2A Serotonergic Receptor Binding

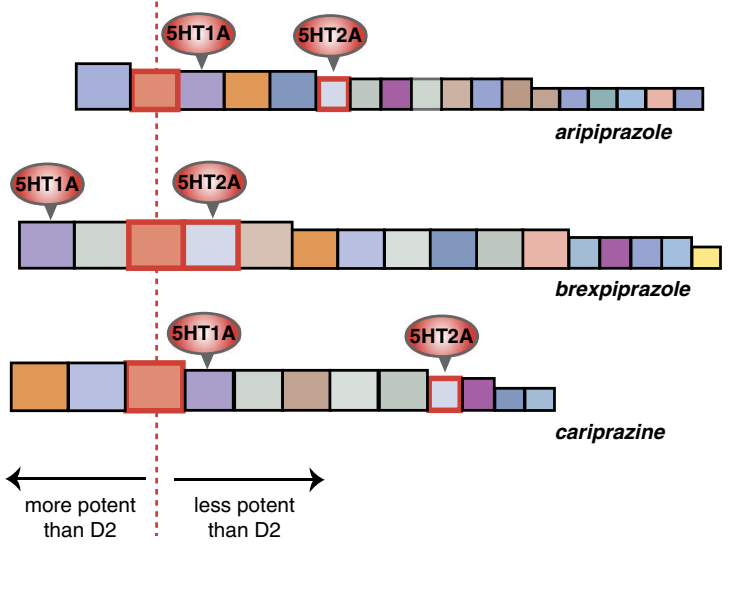

Figure 5. Comparing alpha $1 \mathrm{~B}$ receptor binding of

cariprazine, brexpiprazole, and aripiprazole. The D2

receptor affinity for all compounds is highlighted by a

vertical dotted line. The alpha $1 \mathrm{~B}$ receptor binding

affinities for all compounds are labeled in this figure.

The relative affinities of cariprazine and brexpiprazole

for alpha $1 \mathrm{~B}$ receptors is high, and for aripiprazole,

lower.

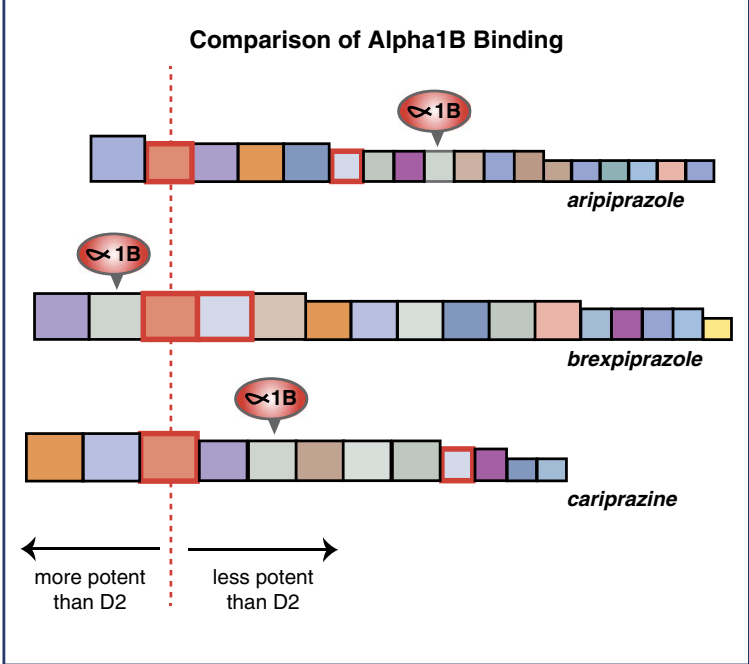

been established, ${ }^{10-12}$ and appear roughly comparable to aripiprazole and brexpiprazole in meta-analyses, ${ }^{11}$ as there are no head-to-head comparisons. Tolerability in terms of weight gain and sedation may be better for cariprazine than for either aripiprazole or brexpiprazole, but akathisia could be comparable or worse, especially compared to brexpiprazole on the basis of meta analyses. ${ }^{11}$ However, further evaluation from the results of clinical experience and head-to-head trials will be necessary to get a better picture of how cariprazine compares to other agents.

\section{Summary}

Cariprazine is a dopamine multifunctional agent acting as a partial agonist at dopamine and serotonin receptors. It is approved both for the treatment of schizophrenia and for manic and mixed episodes associated with bipolar I disorder. Cariprazine has different pharmacologic properties than other atypical antipsychotics, especially a unique high potency blockade of D3 dopamine receptors, which might be linked to unique clinical actions compared to other agents. So far, cariprazine has similar efficacy as other agents and possibly improved tolerability compared to some in terms of weight gain and sedation.

\section{References:}

1. Stahl SM. Stahl's Essential Psychopharmacology., 4th ed. Cambridge, UK: Cambridge University Press; 2013.

2. Stahl SM. Mechanism of action of brexpiprazole: comparison with aripiprazole. CNS Spectr. In press

3. Sautel F, Griffon N, Levesque D, Pilon C, Schwartz J-C, Sokoloff $\mathrm{P}$. A functional test identifies dopamine agonists selective for D3 versus D2 receptors. Neuroreport. 1995; 6(2): 329-332.

4. Freedman SB, Patel S, Marwood R, et al. Expression and pharmacological characterization of the human D3 receptor. J Pharmacol Exp Ther. 1994; 268(1): 417-426.

5. Kiss B, Horváth A, Némethy Z, et al. Cariprazine (RGH-188), a dopamine $\mathrm{D}(3)$ receptor-preferring, $\mathrm{D}(3) / \mathrm{D}(2)$ dopamine receptor antagonist-partial agonist antipsychotic candidate: in vitro and neurochemical profile. J Pharmacol Exp Ther. 2010; 333(1): 328-340.

6. Gyertyán I, Kiss B, Sághy K, et al. Cariprazine (RGH-188), a potent D3/D2 dopamine receptor partial agonist, binds to dopamine D3 receptors in vivo and shows antipsychotic-like and procognitive effects in rodents. Neurochem Int. 2011; 59(6): 925-935.

7. Zimnisky R, Chang G, Gyertyán I, et al. Cariprazine, a dopamine $\mathrm{D}(3)$-receptor-preferring partial agonist, blocks phencyclidineinduced impairments of working memory, attention set-shifting, and recognition memory in the mouse. Psychopharmacology (Berl). 2013; 226(1): 91-100.

8. Duman RS, Duric V, Banasr M, et al. Cariprazine exhibits dopamine D3 receptor-dependent antidepressant-like activity in 
the chronic unpredictable stress model of anhedonia. Neuropsychopharmacology. 2012; 38(Suppl 1): S84.

9. Stahl SM. Role of $\alpha 1$ adrenergic antagonism in the mechanism of action of iloperidone: reducing extrapyramidal side effects. CNS Spectr. 2013; 18(6): 285-288.

10. Stahl SM. Stahl's Essential Psychopharmacology: The Prescribers Guide, 5th ed. New York: Cambridge University Press; 2014
11. Citrome L. The ABC's of dopamine receptor partial agonists: aripiprazole, brexpiprazole and cariprazine: the 15 -min challenge to sort these agents out. Int J Clin Pract. 2015; 69(11): 1211-1220.

12. Kane JM, Zukin S, Wang Y, et al. Efficacy and safety of cariprazine in acute exacerbation of schizophrenia: Results From an international, phase III clinical trial. J Clin Psychopharmacol. 2015 35(4): 367-373. 